\section{MEMORIA DEL FOLLETÍN EN LA PRENSA ROMÁNTICA: HETEROGENEIDAD Y MODOS LITERARIOS EN EL CORREO NACIONAL (1838-1842)}

\author{
Ana María Gómez-Elegido Centeno \\ Universidad Complutense de Madrid \\ anagomezelegido@hotmail.com
}

\begin{abstract}
This paper intends to briefly trace the genesis and evolution of the feuilleton section in the Spanish Romantic press through the example of the newspaperEl Correo Nacional (1838-42). Following the texts published in this press space reveals the initial presence of a considerable diversity of literary forms linked by their entertainment and educational (culture) value. These would later disappear to give way almost exclusively to creative literature and fiction, represented in particular by a new subgenre, the newspaper serial or feuilleton.
\end{abstract}

KEY WORDS: Feuilleton; culture; Literature; fiction (narrative); newspaper serial.

La prensa romántica constituye la cuna del folletín. Durante el período de desarrollo del Romanticismo en nuestro país surge en las publicaciones de la época una sección bajo el rótulo de "Folletín" que supone el primer espacio fijo reservado en las páginas de los periódicos al mundo de la cultura, en general, y la Literatura, en particular. En esta nueva ubicación proliferan textos muy diversos en cuanto a su temática y naturaleza que atraen a un lectorado cada vez más amplio, textos unidos por el denominador común de entretener el ocio, satisfacer la curiosidad y mejorar la formación. Esta sección periodística, caracterizada por la amenidad, funda un nuevo estilo que singulariza no sólo a los textos narrativos que convierten al folletín en género propio y original, sino también a la diversidad de manifestaciones literarias que cumplen con las expectativas de distracción e instrucción de los lectores'.

La moda del folletín, iniciada en las publicaciones francesas $^{2}$, desde su primera aparición en el Journal des Débats hasta su posterior consagración a la novela fragmentada
MEMORY OF THE FEUILLETON IN THE ROMANTIC PRESS; HETEROGENEITY AND LITERARY MODES IN EL CORREO NACIONAL (1838-1842)

RESUMEN: Con este trabajo se pretende trazar sucintamente la génesis y evolución de la sección de folletín en la prensa romántica española a través del periódico El Correo Nacional (1838-42). El seguimiento de los textos publicados en este espacio periodístico permite constatar la presencia inicial de una gran diversidad de manifestaciones literarias unidas por el factor de la amenidad y el de la formación (cultura) que posteriormente irán desapareciendo hasta dejar un protagonismo casi exclusivo a la literatura de creación y ficción representada especialmente en un nuevo subgénero como es el de la novela de folletín.

PALABRAS CLAVE: Folletín; cultura; Literatura; narrativa; novela de folletín.

y serializada en prensa (Romero Tobar, 1973, 45-90), se convierte en requisito obligado en todos los periódicos europeos y americanos del momento. En España el folletín también triunfa clamorosamente en las publicaciones románticas al igual que había ocurrido en las pioneras francesas (Lecuyer y Villapadierna, 1995, 16). Así, los principales diarios madrileños incluyen el folletín desde el Eco del Comercio (1834-42) -que lo define como el lugar de aparición de "aquellos articulillos que besan humildemente los pies del periódico" (10-1-1836, p. 1)-, La Abeja (1835), El Español (1835-37), Revista-Mensajero (1836), El Porvenir (1837-40), El Correo Nacional ${ }^{3}$ (1839-42), La Esperanza (1844), El Clamor Público (1844-64), El Regenerador (1846-48), El Siglo (1848-49) hasta los creados en las décadas de los sesenta, setenta y finales de siglo como La Correspondencia de España, El Heraldo, La América, El Imparcial...

Con el folletín se inaugura un nuevo espacio dedicado a la literatura de evasión y aprendizaje que reúne a todos los 
sectores sociales en torno al periódico ${ }^{4}$. Este interés común alrededor de este apartado periodístico tiene su razón en la diversidad y la heterogeneidad de sus escritos ${ }^{5}$, lo que permite complacer en mayor medida las expectativas lectoras.

En este trabajo, tras el estudio hemerográfico de la sección folletinesca de El Correo Nacional (1838-42) ${ }^{6}$, se concluye la gran variedad de sus manifestaciones literarias, variedad demostrada en una clasificación temática donde se distinguen los siguientes grupos de textos:

- Los Boletines: "Boletín científico e industrial" y "Boletín bibliográfico" -figura alternativamente con los subtitulos: "Noticia de las obras publicadas últimamente en España y fuera de ella", o bien "Noticias de obras publicadas en España y otros países"-. Ambos boletines informan y comentan las noticias, descubrimientos y avances mundiales en el ámbito científico e industrial y las novedades bibliográficas ${ }^{7}$ (ver El Correo Nacional, 24 de enero de 1840).

- Otro de los temas que reúne gran interés para los lectores es el de los toros. Estas crónicas suelen estar firmadas por Abenámar (Santos López Pelegrín) ${ }^{8}$ y ocupar la primera página, o bien las dos primeras. Los textos van encabezados con el rótulo "Toros" o "Toros (y novillos)"

- Un numeroso grupo de artículos trata asuntos tan variopintos como: noticias e informaciones sobre actividades de instituciones culturales -el Ateneo, el Liceo y la Universidad-, o bien exposiciones y museos ${ }^{10}$, sociedad en general y educación femenina en particular ${ }^{11}$-tenemos, por ejemplo, De la educación de las madres de familia o de la civilización del género humano por las mujeres, de L. Aime-Martín, serie de numerosas entregas que irá de 1838 a 1839 (ver El Correo Nacional, 22 de mayo de 1838)-, tratados y artículos ensayísticos de divulgación sobre diversas disciplinas en una o varias entregas -Arte, Filosofía, Psicología, Historia, Derecho, Literatura, Geometría, Periodismo... ${ }^{12}-$, artículos formativos sobre curiosidades y "Maravillas" de la naturaleza ${ }^{13}$, costumbres y peculiaridades de distintos países, literatura de viajes, expediciones y descubrimientos geográficos ${ }^{14}$-reflejo de la moda romántica del orientalismo y el exotismo en muchos casos-, biografías y artículos sobre personajes históricos, famosos y pintorescos -a veces, tipos cos- tumbristas ${ }^{15}-$, necrologías ${ }^{16}$, incluso causas y procesos judiciales ${ }^{17}$.

De esta manera el folletín, como sección fija dentro de la prensa diaria, reúne en un mismo lugar informaciones y textos que antes habían sido, en el caso de periódicos del setecientos, objeto central y único de prensa especializada. Así, la presencia de los Boletines -con su información bibliográfica-, de la crítica literaria y de la actualidad y actividades culturales tiene como claro precedente una publicación como el Diario de los literatos de España en que se reducen a compendio los escritos de los autores españoles y se hace juicio de sus obras (1737) -fundado por Francisco Manuel de Huerta, Juan Martínez Salafranca y Leopoldo Jerónimo Puig- primer periódico español consagrado a estas parcelas culturales y el que inaugura las relaciones entre Literatura y Periodismo (Urzainqui, 1995, 125-216).

- Asimismo un importante conjunto de textos dentro del folletín está inspirado por la realidad política nacional e internacional que da lugar al periodismo de opinión ${ }^{18}$. Aquí contamos con la firmas de escritores como Abenámar, Gabriel García y Tassara, o Antonio María Segovia (El Estudiante), habituales colaboradores de este periódico y asimismo nombres frecuentes en otros diarios y revistas románticos como es el caso del Semanario Pintoresco Español.

- Otro de los apartados dentro de esta sección recoge la correspondencia y escritos a otros periódicos como la dirigida al Eco del Comercio, el Guirigay, El Mensajero del Pueblo, El Conservador o Fray Gerundio, con los que se mantiene una cierta polémica. También se incluyen textos compuestos en forma epistolar ${ }^{19}$, comunicados y remitidos diversos, o bien se reproducen artículos de otros periódicos como el Semanario Pintoresco ${ }^{20}$-así, "Biografía española. El príncipe Ali Bey El Abbassi" (Don Domingo Badia Leblich). (Del Semanario Pintoresco, del domingo último), de 7-3-1838, o bien "Industria española. Exposición pública de 1841" (Del Semanario Pintoresco), de 10-1-1842 -también en el n. ${ }^{\circ}$ 1.445-.

En este seguimiento de la sección folletinesca de El Correo Nacional se comprueba la convivencia primero, y el paso mayoritario y casi exclusivo, después, de textos de naturaleza miscelánea -como se ha visto anteriormente- a 
otros de naturaleza ya específicamente literaria. En cuanto a la presencia de la Literatura aparece en las formas de la crítica literaria en general, junto a la teatral, y la propia literatura de creación y ficción -poemas, cuentos y novela-.

Atendiendo al carácter genérico se distingue un primer grupo ubicado bajo el título "Poesía" y un segundo grupo dedicado a la narrativa. En ocasiones en el espacio folletín aparece simultáneamente lo literario creativo junto a otro tipo de textos. Así en el n. ${ }^{\circ} 6$ (21-2-1838) tenemos el poema de Gil y Carrasco La isla desierta -pp. 1 y 2-, junto a otros dos escritos teórico-divulgativos bajo el rótulo de "Variedades" -también dentro del folletín (p. 2)-; lo poético se combina con lo bibliográfico en el n. 109 (46-1838) que en sus primeras páginas presenta información literaria bibliográfica y en la p. 3 el poema de Antonio Ferrer La eternidad, o en el n. 189 (23-8-1838) en que en la sección folletín aparece la poesía A Burgos, de J. Guillén Buzarán y en "Variedades" una obra narrativa: La novena de la Candelaria.

El folletín dedicado al teatro presenta información y crítica de las obras de la cartelera madrileña -solo en un número se refiere a Barcelona, en el n. ${ }^{\circ}$ 757: "Noticias teatrales. El teatro de Barcelona"- titulándose: "Boletín de teatros", "Crítica teatral" o "Teatros". En ocasiones el antetítulo se refiere a los teatros concretos en que tiene lugar la representación como el Teatro del Príncipe (ver El Correo Nacional, 4 de octubre de 1838) y el Teatro de la Cruz. Asimismo se presenta la crítica operística y de otros espectáculos ${ }^{21}$. Normalmente los artífices de ellas son Enrique Gil y Carrasco y Ventura de la Vega. En cuanto a la crítica literaria en la mayoría de los casos tiene como autor a García y Tassara ${ }^{22}$, que junto a Santos López Pelegrín y Antonio María Segovia, como hemos visto, escriben frecuentemente en estas páginas. También conviven en la sección la crítica teatral junto a otro tipo de textos como ocurre en el n. 143 (87-1838, pp. 1-2) donde comparte espacio con la serie De la educación de las madres de familia o de la civilización del género humano por las mujeres.

La poesía aparecida dentro del folletín alterna desde la sentimental romántica, a la de circunstancias, o la política y satírica de Abenámar. Los textos poéticos suelen ocupar las dos primeras páginas y se publican obras de escritores como José Zorrilla -Poesía (n. 3, p. 1)-, Enrique Gil y Carrasco - La isla desierta (n. ${ }^{\circ}$ 6, pp. 1-2), La mariposa (n. 27, p. 4), Un ensueño (n. 58, p. 1), La nube blanca (n. 201, p. 1), Meditación (n. ${ }^{\circ} 236$, p. 1), Versos insertos en el álbum de una señora. La mujer y la niña (n. ${ }^{\circ} 243$, p. 1) (ver El Correo Nacional, 16 de octubre de 1838)-, Francisco González Elipa -El honor (n. ${ }^{\circ} 87$, p. 1)-, Antonio Ferrer - La eternidad (n. ${ }^{\circ} 109$, p. 1)-, J. Guillén Buzarán -A Burgos (n. ${ }^{0} 189$, p. 1)-, Abenámar -Batalla de los capotes con las capas (n. ${ }^{\circ} 408$, p. 1 y n. ${ }^{\circ} 436$, p. 1), El desierto (n. 459. p. 1)-, Salvador Bermúdez de Castro -El amor (n. ${ }^{\circ} 716, p$. 1)-, García y Tassara - En el campo (n. ${ }^{\circ}$ 511, p. 1), La ilusión (n. ${ }^{\circ} 564$, p. 1), A los poetas (n. ${ }^{\circ} 704$, p. 1), El desvelo (n. ${ }^{\circ}$ 714, p.1), Canto bíblico (n. 1.516 , pp. 1-2)-, J.M. Díaz -A S.M. la Reina Doña María Cristina (n. ${ }^{0} 1.036$, pp. 1-2)- ${ }^{23}$... También hallamos poesías en la sección de "Variedades" ( $p$. 4), al final del periódico.

Los textos narrativos del folletín desvelan el muestrario de las fórmulas literarias románticas con relatos cortos, cuentos -a veces con subtítulos de "cuento romántico" como La luna de enero. Cuento romántico, por J. N. V (20-3-1840) (ver El Correo Nacional, 20 de marzo de 1840), o "cuento fantástico" como en La noche de máscaras. Cuento fantástico, por A. (17-6-840) con dos entregas más $-n .{ }^{\circ} 889$ y n. ${ }^{\circ} 891-$. Tenemos asimismo artículos literarios, artículos costumbristas y otros relatos en una 0 varias entregas ${ }^{24}$ junto a las novelas ${ }^{25}$ en su mayor parte procedentes de la traducción de obras de escritores extranjeros, sobre todo franceses, como Federico Soulié, George Sand y Alejandro Dumas, y que ocupan de manera exclusiva las páginas del folletín durante muchos números sucesivos aplazando la publicación de otro tipo de textos. Como practicantes del género narrativo en estas páginas de El Correo Nacional contamos con J. M. de Mas y Casas, E. Gil y Carrasco, J. M. Díaz, Salvador Bermúdez de Castro, García y Tassara y Antonio Ros de Olano (A. y A. L.).

La novela se convierte en protagonista indiscutible del espacio folletín de manera que las entregas novelescas relegan a un segundo lugar, sobre todo a partir de 1840, la publicación en esta sección de otro tipo de textos. En El Correo Nacional la frecuencia de dedicación a este género narrativo es máxima en el período de los años 1840-1842. Si bien en 1838 encontramos algunas novelas como Una flor. Novela original de costumbres, de J. M. Díaz (ver El Correo Nacional, 5 de noviembre de 1838), y en 1839 Margarita y Florita, es a partir de 1840 cuando 
se incrementa considerablemente su número y así en este año tenemos un total de once obras salidas en el folletín: Un sueño de amores, Cristela, La cruz del acecho, Libro de memorias de Elisa. Libro de sus lágrimas, Edith de Falsen, La posada de la baronesa, Las dos cartas, Los acreedores, Madame Laffarge, El incendiario de Aveiron y Lavinia. De 1841 son: Mateo Petit o el beso de despedida, El secreto de la confesión, El secreto de una madre, El orgullo de un nombre, Ana de Arcona, La Mulata, Hugo Lawlor o el novio de Varna, Las cuatro hermanas, Un corsario. Bajo el imperio del terror y, por último, en 1842 se publican largas novelas como El caballero d'Armental (ver El Correo Nacional, 26 de enero de 1842) y Los novios, de F. Soulié26.

El torrente folletinesco narrativo irrumpe en las páginas periódicas hasta el punto de terminar por identificarse el folletín con una particular clase de novela por entregas -el folletín novelesco, la novela folletinesca- que adopta el nombre del título de la sección en que aparece y que ofrece una serie de características derivadas, entre otros factores, de su nacimiento y difusión a través del soporte periodístico de comunicación mayoritaria. La novela de folletín presentará una configuración estilística marcada por la estrategia de atraer al lector por la fascinación, el suspense, el misterio y la intriga de sus temas y contenidos, las peripecias, aventuras y desventuras de sus héroes y heroínas, y la carga sentimental y melodramática de sus argumentos.

El lector de esta novela manifiesta una fidelidad inquebrantable al periódico del que depende el "continuará" del folletín, periódico que seguirá comprando hasta conocer el final de la novela y al que volverá por el aliciente y la promesa, muy bien anunciada, del inicio de otras nuevas y más interesantes historias ${ }^{27}$. La novela de folletín, con sus rasgos y estructura particulares, ingresará en la llamada cultura popular. Y su primera peculiaridad viene marcada por su lugar y modo de publicación. Desde su origen en la prensa romántica, en un lugar fijo y en una sección determinada, el folletín ha desplegado una larga vida. La vigencia como peculiar modalidad literaria continúa en nuevas formas que aprovechan algunos de sus elementos en su afán de captación del público espectador y lector. Es el caso de manifestaciones paraliterarias como la novela rosa, los seriales radiofónicos, las fotonovelas, los culebrones televisivos, los microrrelatos escritos para teléfonos móviles en diversas entregas... 0 la resurrección de las novelas folletinescas a partir del nuevo soporte electrónico de Internet -folletín digital-. Precisamente a modo de homenaje a uno de los géneros más populares del s. XIX, el Museo Romántico, a través de la revista digital Somosmalasaña, creó el Folletín del Museo, una publicación on-line, donde en diversas entregas e imitando el estilo de los folletines decimonónicos, fue contando cómo fue el proceso de compra, transporte y restauración del retrato de Isabel II pintado por Madrazo hasta llegar a sus salas de exposición ${ }^{28}$. Con esta iniciativa se brindó el mismo recuerdo que se ha intentado hacer con este artículo, breve memoria sobre un estilo y un género de ayer, de hoy y de siempre, surgido en los albores del Romanticismo.

\section{NOTAS}

1 En este sentido hay que decir que las manifestaciones escriturales que figuran en esta sección remitirian a la concepción dieciochesca, y por tanto enciclopédica, que se tenía de la Literatura como rama del arte y del saber que abarcaba textos no sólo creativos y de ficción, sino también los pertenecientes a disciplinas como la Historia, la Filosofía, etc.

Recibido: 20 de junio de 2012 Aceptado: 5 de julio de 2012
2 En principio se trata de un cuadernillo publicado por el periódico Journal des
Débats, una especie de suplemento dedicado a la crítica literaria y donde se trataban de vez en cuando algunos temas de carácter diverso (Brunori, $1980,23)$. Posteriormente pasa a ser el lugar reservado, ya dentro de la prensa diaria, en el tercio inferior de la primera página $-\mathrm{y}$ ocupando esta primera y algunas más- a todos aquellos textos dedicados a la difusión de ideas, curiosidades, crítica y creación literaria, es decir, un cajón de sastre donde se incluia lo no estrictamente informativo-noticioso- 
político. Émile de Girardin, creador de La Presse, es el inspirador de esta idea, guiado por el objetivo de vender más periódicos bajando su precio y compensándolo con la publicación de anuncios pagados y de escritos que interesen al potencial comprador. Con ello los lectores habituales de prensa ven ampliado su horizonte de posibilidades y se consigue además un nuevo lectorado cuyo reclamo es precisamente esta sección.

3 En El Correo Nacional Antonio María Segovia (El Estudiante), uno de los colaboradores habituales de esta sección lo define así, en función de su ubicación, en el artículo en que se presenta ante el lector: "Aquí, señores, en este rinconcito del gran periódico madrileño, del papel de la nueva escuela, del diario ecléctico romántico; en una palabra, del Correo Nacional. ¿Qué? ¿No me encontráis todavía? Pues yo os daré las señas.

- Poned el dedo índice de la derecha mano sobre ese gran rótulo que en letra gótica elegante dice El Correo Nacional, colocado como si dijéramos en el polo ártico del pliego; bajar ahora verticalmente sin separar un punto el dedo de la superficie del papel (...). Ahora bien, ¿no veis ahí una gran raya negra que atraviesa a manera de línea equinnocial toda la extensión del papelote, dividiéndolo en dos grandes pero desiguales hemisferios? Pues aqui, en la parte baja, o del meridión, en el hemisferio austral, en el África de El Correo, vamos a decir, que llaman folletín en el tecnicismo periodístico, es en donde su director nos ha concedido campo franco a ABENÁMAR y a mí para esgrimir nuestras satíricas armas contra los enemigos de la razón y la verdad" ("El Estudiante aqui", El Correo Nacional, n. ${ }^{\circ} 392,14-3-1839$, p. 1).
4 Es ilustrativa a este respecto la anécdota que recoge Monguió: "No es difícil comprender que el proletariado urbano, al que el crecimiento del capitalismo y de la industria moderna española durante el siglo XIX sometía más y severamente a largas jornadas de trabajo en fábricas y destajos, hallaba en esos novelones un medio de escapar imaginativamente a la monotonía de su diaria vida explotada. (...) tampoco es difícil comprender que la clase media, de trabajadores de cuello y corbata, confinada también durante largas horas tras una mesa de oficina o un mostrador de almacén hallase igualmente, en esas novelas la visión imaginada de la vida de acción, aventuras, pasión y hasta violencia, que ella se denegaba. Algo menos fácil es entender que personas de alta categoría social y con acceso a la cultura superior disfrutasen también con la lectura de esos novelones: Ríos Rosas, por ejemplo, en cierta ocasión hizo aguardar más de media hora a un Ministro que fue a visitarle entretanto él devoraba el folletín del periódico de la mañana, un novelón titulado Las primas de Satanás". Monguió, Luis (1951): "Crematística de los novelistas españoles del siglo XIX", Revista Hispánica Moderna, XVII, p. 115.

5 En el s. XVIII hallamos en creadores de publicaciones periódicas el intento de llegar al lector a través de la diversidad literaria y cultural. Así contamos con el precedente de Francisco Mariano Nipho con su Cajón de sastre (176162), donde intenta ir más allá de lo habitual informativo de las gacetas, 0 bien su Novelero de los estrados y tertulias y diario universal de bagatelas (1764), donde incluye, por ejemplo, la traducción de cuentos de Marmontel. Pero es ahora cuando esta intención de captar al público brindándole la oportunidad del entretenimiento y la formación tiene un lugar concreto, una localización especifica dentro de toda la prensa diaria, bajo el membrete de una sección nueva.

6 Periódico de cuatro páginas fundado por Andrés Borrego que empieza en febrero de 1838 y termina una primera etapa en junio del mismo año. Acaba en 1842, despidiéndose del público en el n. 1.597 (miércoles, 15-6). Seguirá la línea de "El Español", anterior publicación de Borrego que cesó a finales de 1837 y a partir del n. ${ }^{\circ} 1.304$ (sábado, 21-8-1841) figura como "El Correo Nacional". Continuación del primitivo "El Español" (de agosto a diciembre de 1841 es cuando figura tal subtítulo). En la cabecera aparece el precio de suscripción de 12 reales al mes en Madrid. Secciones: Noticias extranjeras, Cortes, El Correo (de la situación de país), Gacetilla de la Corte, Espectáculos, Folletín, Anuncios, Bolsa... Luego se incorporan otras secciones como Guerra Civil e información por provincias de la marcha de ésta. En 1841 aparecen nuevas secciones como la dedicada a la publicación de diversos documentos remitidos, 0 bien, el parte comercial, los actos del gobierno, comunicados, sección literaria, crítica literaria, teatros, boletín de moda, A última hora.

7 Aparece esta modalidad dentro de la sección folletín en los siguientes números del periódico:

"Boletín científico e industrial": 1838: jueves, 22-2, n. 7 , pp. 1-3, n. 11 (Variedades. Consideraciones sobre la importancia y lo agradable de los conocimientos químicos) n. 14, n. 22, n..$^{30}$ n. n. 35, n. ${ }^{0} 44$ n. 52, n. ${ }^{\circ} 57$, n. 07, n. 072, n. ${ }^{0} 77$, n. 85, n. 93, n. ${ }^{\circ} 99$, n. ${ }^{\circ} 117$, n. ${ }^{\circ} 123$ 
n. ${ }^{\circ} 128, n .^{\circ} 136, n .^{\circ} 144, n .^{\circ} 151$, n. ${ }^{\circ} 158$, n. ${ }^{\circ} 165$, n. ${ }^{\circ} 172$, n. 180 , n. ${ }^{\circ} 186, n .0^{\circ} 193, n .0200, n .0207$, n. ${ }^{\circ} 214, n .^{\circ} 222, n .0^{\circ} 235, n .^{\circ} 242$, n. ${ }^{\circ} 250, n \cdot{ }^{\circ} 264, n .^{\circ} 278, n .^{\circ} 290$, n. ${ }^{\circ} 298$, n. ${ }^{\circ} 305$, n. ${ }^{\circ} 319.1839$ : lunes, 7-1, n. ${ }^{\circ} 326$, pp. $1-3$, n. ${ }^{\circ} 337$, n. ${ }^{\circ} 347$, n. ${ }^{\circ} 354$, n. ${ }^{\circ} 361, n .{ }^{\circ} 368, n .^{\circ} 375$, n. ${ }^{\circ} 382, n .{ }^{\circ} 389, \quad n .{ }^{\circ} 396, n .{ }^{\circ} 403$, n. 416, n. 423, n. 040, n. 437 , n. ${ }^{\circ} 444$, n. ${ }^{\circ} 451$, n. ${ }^{\circ} 458$, n. ${ }^{\circ} 465$, n. ${ }^{\circ} 472$, n. ${ }^{\circ} 479, \quad$ n. ${ }^{\circ} 486, n .{ }^{\circ} 493$, n. ${ }^{\circ}$ 500, n. ${ }^{\circ}$ 507, n. ${ }^{\circ} 514$, n. ${ }^{\circ} 521$, n. ${ }^{\circ} 528$, n. ${ }^{\circ} 535, \quad$ n. ${ }^{\circ} 542, \quad$ n. ${ }^{\circ} 549$, n. ${ }^{\circ} 555, \quad$ n. ${ }^{\circ} 563, \quad$ n. ${ }^{\circ} 570, n \cdot{ }^{\circ} 577$, n. ${ }^{\circ} 584$, n. ${ }^{\circ} 591$, n. ${ }^{\circ} 605, n .{ }^{\circ} 626$, n. 633, n. ${ }^{\circ} 670$, n. ${ }^{\circ} 677$, n. ${ }^{\circ} 684$, n. ${ }^{\circ} 691$, n. ${ }^{\circ} 698, \quad$ n. ${ }^{\circ} 705, \quad$ n. ${ }^{\circ} 712$. 1840: lunes, 6-1, n. 719 , pp. 1-2 (Física del globo). Este Boletín se publicará casi todos los lunes y martes de este año: n. ${ }^{\circ} 726, n .^{\circ} 734, n .^{\circ} 740$, n. ${ }^{\circ} 747$, n..$^{0754,}$ n. ${ }^{\circ} 761, n .{ }^{\circ} 769$, n. ${ }^{\circ} 776$, n. ${ }^{\circ} 782$, n. ${ }^{\circ} 792$, n. ${ }^{\circ} 796$, n. ${ }^{\circ} 811,824, n .^{\circ} 832, n .^{\circ} 838$, n. $^{\circ} 851$, n. ${ }^{\circ} 867$, n. ${ }^{\circ} 894$, n. ${ }^{\circ} 908$, n. ${ }^{\circ} 913$, n. ${ }^{\circ} 920$, n. 927, n. 934, n. ${ }^{\circ} 961$, n. ${ }^{\circ} 965$, n. 975, n. ${ }^{\circ} 990, n .^{\circ} 1.007$, n. ${ }^{\circ} 1.014$, n. ${ }^{\circ} 1.022$. 1841: lunes, $18-$ 1, n. ${ }^{0} 1.091$, pp. 1-2: n. 1.149, n. ${ }^{1.169,}$ n. ${ }^{\circ} 1.186, \quad$ n. 1.219 , n. ${ }^{\circ} 1.231$, n. 1.237, n. 1.244 , n. ${ }^{\circ} 1.251, \quad$ n. $1.265, \quad n .01 .272$, n. ${ }^{\circ} 1.279, \quad$ n. $1.286, \quad n .01 .292$, n. ${ }^{\circ} 1.299, \quad$ n. $1.306, \quad$ n. $1-312$, n. ${ }^{1-317,}$ n. ${ }^{0} 1.333, \quad$ n. 1.340 , n. ${ }^{\circ} 1.347, \quad$ n. ${ }^{\circ} 1.353, \quad$ n. 1.360 , n. $1.368, \quad$ n. $1.380, \quad$ n. 1.394 , n. ${ }^{\circ} 1.402, \quad$ n. ${ }^{\circ} 1.409, \quad$ n. 1.415 , n. ${ }^{\circ} 1.425 .1842$ : lunes, $3-1, n .^{\circ} 1.437$, pp. 1-2.

"Boletín bibliográfico": 1838: lunes, 5-3, n. 18, pp. 1-2; n. ${ }^{\circ} 32$, n. ${ }^{\circ} 46, n .{ }^{\circ} 61, n .{ }^{\circ} 64, n .{ }^{\circ} 82, n .{ }^{\circ} 109$, n. ${ }^{\circ} 137$, n..$^{0} 162$, n. ${ }^{\circ} 183$, n. ${ }^{\circ} 196$, n. ${ }^{\circ} 220$, n. ${ }^{\circ} 240$, n. ${ }^{\circ} 259, \quad$ n. ${ }^{\circ} 295$, n. ${ }^{\circ} 313$. 1839: jueves, 24-1, n. ${ }^{\circ} 343$, pp. 1-2. n. ${ }^{\circ} 363$, n. ${ }^{\circ} 379, n .^{\circ} 400$, n. ${ }^{\circ} 462$, n. ${ }^{\circ} 483$, n..$^{497,}$ n. ${ }^{\circ}$ 518, n. 559, n. 623, n. 689, n. 701. 1840: viernes, 24-1, n. ${ }^{\circ} 737$, pp. 1-2: Boletín bibliográfico. También aparece en: n. ${ }^{\circ} 773$, n. ${ }^{\circ} 803$, n. ${ }^{\circ} 813$, n. ${ }^{\circ}$ 930. 1841: lunes, 8-2, n. ${ }^{0} 1.112$, pp. 1-2 y en n. ${ }^{\circ} 1.302, n .{ }^{0} 1.343$ y n. 1.389 . 1842: miércoles, 5-1, n. 1.439 , pp. 1-3: Bibliografía y en n. ${ }^{\circ} 1.440$.

8 M. ${ }^{\text {a }}$ Celia Forneas Fernández estudia esta faceta del autor en su artículo "Abenámar, periodista taurino", Revista de estudios taurinos, n. ${ }^{\circ} 10, \mathrm{Se}-$ villa, 1999.

9 1838: jueves, 29-11, n. 287, p. 1: Toros, de Abenámar. 1839: miércoles, 16-1, n. 335 , p. 1: Toros (y novillos) y en: $n .{ }^{\circ} 342$, Toros (y novillos), n. ${ }^{\circ} 350$, n. ${ }^{\circ} 362$, n. ${ }^{\circ} 362$, n. ${ }^{\circ} 388$, pp. 1-2: $Y$ va de toros, n. ${ }^{\circ} 419$, n. ${ }^{\circ} 425, n .^{\circ} 433$, n. ${ }^{\circ} 439$, n. ${ }^{\circ} 447$, n. ${ }^{\circ} 467$, n. ${ }^{\circ} 482$, n. ${ }^{\circ} 488$, n. ${ }^{\circ} 494$, p. 1 : Toros y comilonas, por Abenámar, n. ${ }^{\circ} 523$, n. ${ }^{\circ} 558$, n. ${ }^{\circ} 568$, n. ${ }^{\circ} 572$, n. ${ }^{\circ} 586$ n. ${ }^{\circ} 603$, n. ${ }^{\circ} 607$, n. 614, n. ${ }^{\circ} 680.1841$ : jueves, $6-5, n .{ }^{\circ} 1.198, n *^{\circ} 1.206$, p. 1: Toros, por Merlín, n. 1.211, por Merlín, n. ${ }^{0} 1.217$, n. ${ }^{\circ} 1.222$, p. 1: Los picadores del lunes y el gobernador de Cartagena, n. $1.224, n .^{\circ} 1.232$, n. ${ }^{\circ} 1.239$, n. 1.250, n..$^{\circ} 1.253$.

10 1839: jueves, 21-3, n. 399 , pp. 1-3: Liceo de Madrid. Peroración de El Estudiante; martes, 26-3, n. ${ }^{\circ} 404$, pp. 1-2: Conferencia literaria en el Ateneo de esta Corte; jueves, 28-3, n. ${ }^{\circ}$ 406, pp. 1-3: Cátedras científicas, artísticas y literarias de Madrid. Sigue en: n. 411 , pp. 1-2 y n. ${ }^{\circ} 449$, pp. 1-3; viernes, $12-4$, n. ${ }^{\circ} 420$, pp. 1-2: Revista de cursos literarios y científicos; sábado, 1-6, n. ${ }^{\circ}$ 470, pp. 1-2: Conferencias del Ateneo; martes, 20-8, n. ${ }^{\circ}$ 550, p. 1: El Liceo, por Abenámar; martes, 24-9, n. ${ }^{\circ} 585$, p. 1: Exposi- ción pública de nobles Artes, por A. de S., Duque de Rivas.

11 1838: martes, 22-5, n. 96, pp. 1-2: De la educación de las madres de familia o de la civilización del género humano por las mujeres, por L. AimeMartin. Continúa en: n. ${ }^{\circ} 97$, n. ${ }^{\circ} 98$, n. $102, \quad$ n. $119, \quad$ n. $12, \quad$ n. ${ }^{\circ} 122$, n. 124, n. $130, n .{ }^{\circ} 140, n .{ }^{\circ} 141$, n. 142, n. 143, n..$^{\circ} 145$, n. ${ }^{\circ} 146$, n. ${ }^{\circ} 147$, n. ${ }^{\circ} 148$, n. ${ }^{\circ} 149, \quad$ n. ${ }^{\circ} 153$, n. $154 ;$ n. ${ }^{\circ} 155$, n. ${ }^{\circ} 156$. Se continúa en 1839: n. ${ }^{\circ} 370$, n. ${ }^{\circ} 371$, y n. ${ }^{\circ} 372$. 1839: viernes, 26-4, n. ${ }^{\circ} 434$, pp. 1-2: Ventajas de la educación; jueves, 187, n. 517, pp. 1-3: De la condición social de las mujeres, especialmente en Inglaterra, por Philarata Chasles. 1842: viernes, 3-6, n.* 1.585, pp. 1-2: Las mujeres oradoras. Addisson; sábado, 22-1, n. ${ }^{\circ}$ 1.456, pp. 1-2: Magnífico baile en las Tullerías.

12 1838: martes, 20-2, n. ${ }^{\circ}$ 5, pp. 1-3: "Bellas Artes. Caracteres de una nueva reforma artística. Paganismo y Cristianismo", de P. de Madrazo, continuado en n. ${ }^{\circ}$ 9; jueves, 13-9, n. 210, pp. 1-2: Museo Nacional de la Trinidad, de F. Van Halen;

1839; lunes, 1-4, n. ${ }^{\circ} 409$, pp. 1-3: Literatura. De las formas del teatro inglés y del español, A. L.; domingo, 14-4, n. ${ }^{\circ} 422$, pp. 1-3: Resumen de varios artículos anteriores sobre el Romanticismo, por A.L.; domingo, 5-5, n. ${ }^{\circ} 443$, pp. 1-3: Breve compendio de la Historia de Inglaterra. Continúa en: n. $.^{446}, n .^{\circ} 448, n .^{\circ} 453, n .^{\circ} 456$, n. ${ }^{\circ} 462$; miércoles, $5-6,{ }^{\circ} 474$, p. 1 : La unidad, o consideración filosófica sobre la identidad de los principios de las Matemáticas, de la Gramática general y de la religión cristiana. Continúa en: n. ${ }^{\circ} 475$, n. ${ }^{\circ} 476$, n. ${ }^{\circ} 477$ y n. ${ }^{\circ} 481$; sábado, 22-6, n. ${ }^{\circ} 491$, p. 1 : Los doce trabajos de los Hércules periodistas, El Estudiante; jueves, 27-6, 
n. ${ }^{\circ}$ 496, pp. 1-2: Examen de la sentencia de Jesucristo que han publicado varios periódicos, por el abad Laval; domingo, 7-7; n. ${ }^{\circ}$ 506, pp. 1-2: Revista de antigüedades romanas en Cataluña; jueves, 11-7, n. ${ }^{\circ}$ 510, pp. 1-3: Filosofía. La Psicología y la Frenología comparadas, por M. Adolfo Garnier (1); domingo, 21-7, n. ${ }^{\circ}$ 520, pp. 1-2: El periodismo, G. y Tassara; jueves, 15-8, n. ${ }^{\circ}$ 545, pp. 1-2: Un literato, G. y Tassara; sábado, 24-8, n. ${ }^{\circ} 554$, pp. 1-2: Introducción a una ojeada histórica de los progresos del entendimiento humano; jueves, 2410, n. ${ }^{\circ} 615$, p. 1: Lecciones de Derecho español, por el Dr. D. Vicente Hernández de la Rua; sábado, 16-11, n. ${ }^{\circ} 668$, pp. 1-3: Legislación. Historia de la imprenta y de las leyes relativas a ella en Inglaterra. Sigue: $n .{ }^{\circ} 669$ y n. ${ }^{\circ} 674$; miércoles, 4-12, n. ${ }^{\circ} 686$, pp. 1-2: De la prensa periódica, G. y Tassara; domingo, 15-12, n. ${ }^{\circ} 697$, pp. 1-3: La Revolución y el Pueblo, en n. 702 acaba. Por T. 1840: jueves, 2-1, n. 715, pp. 1-3: Conocimientos útiles. Tratado de Geometría que continúa en: n. ${ }^{\circ} 730$, n. ${ }^{\circ} 749$, n. 750, n. 751, n. 755 у п. ${ }^{0} 758$; sábado, 11-4, n. ${ }^{\circ} 815$, pp. 1-2: La crítica y el genio; martes, 9-6, n. ${ }^{\circ} 872$, p. 1: Una obra de escultura, por A. Ros de Olano; martes, 4-8, n. ${ }^{\circ}$ 928, pp. 1-3: Estado actual de la Literatura europea, por A.L.; martes, 1-12, n. ${ }^{0}$ 1.043, pp. 1-3: Pesas, medidas y monedas. Sigue en: $n .{ }^{\circ} 1.044$ de este mismo año, y después ya en 1841 en: n. ${ }^{\circ} 1.134$, n. ${ }^{\circ} 1.135$, n. ${ }^{\circ}$ 1.170. Por Vicente Vázquez y Queipo.

13 1839: domingo, 30-6, n. 499, pp. 1-2: Maravillas de la naturaleza. Emigración de las aves en la América del Norte; domingo, 14-7, n. ${ }^{\circ}$ 513, pp. 1-2: Maravillas del mar. La ballena y en n. ${ }^{\circ} 536$, pp. 1-2: Maravillas de la Naturaleza. El león; miércoles, 13-11, n. ${ }^{\circ} 665$, pp. 1-3: Historia natural. Fecundidad de los mamíferos y proporciones relativas de los sexos en los animales vertebrados.

14 1839: sábado, 23-2, n. ${ }^{\circ} 373$, pp. 1-3: Viajes. Expedición a la Laponia y a la nueva Zemble; miércoles, 13-3, n. ${ }^{\circ}$ 391, pp. 1-3: Viaje a Tombuctú. Sigue en: n. ${ }^{\circ} 401, n .^{\circ} 429:$ Variedades: artículo III de Viaje a Tombuctú, pp. 3-4, y de nuevo en folletín en n. ${ }^{\circ} 431$, pp. 1-3; sábado, 20-4, n. ${ }^{\circ} 428$, pp. 1-2: Costumbres y usos judiciales de la Bosnia; domingo, 236, n. 492 , pp. 1-3: Miseria del pueblo de Irlanda (I); jueves, 25-7, n. ${ }^{\circ}$ 524, pp. 1-2: Geografía física. Noticia acerca de dos tentativas de subida al monte Chimboraza, por M. de Humboldt. Sigue en: n. 527 y n. ${ }^{0} 529$; viernes, 9-8, n. ${ }^{\circ}$ 539, pp. 1-3: De las musulmanas; jueves, 5-9, n. ${ }^{\circ}$ 566, pp. 1-2: Comunicación con la India por Egipto y el mar Rojo. Continuación: n. ${ }^{\circ} 581$, pp. 1-3; viernes, 8-11, n. 630 , pp. 1-3: Descubrimiento de la Florida; n. 673 , pp. 1-2: Cuadro de las fiestas con que la provincia de Álava ha celebrado la confirmación de sus fueros, por V. 0.; sábado, 2812, n. ${ }^{\circ} 710$, pp. 1-2: Geografía. Habitantes de la Tierra del fuego.

1840: sábado, 8-2, n. 752 , pp. 1-3: Argel. Su conquista por los franceses; lunes, 17-8, n. 941, pp. 1-3: Costumbres de Europa en los siglos XV y XVI; miércoles, 19-8, n. ${ }^{\circ}$ 943, pp. 1-3: De la Irlanda social, política y religiosa; jueves, 20-8, n. 944 , pp. 1-3: Pensamientos inspirados por una visita al Real Monasterio de El Escorial, por A.G.; martes, 27-10, n. ${ }^{\circ} 1.008$, pp. 1-2: La Arabia y sus ciudades santas.

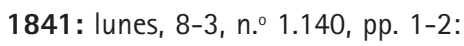
El Bautismo de los Trópicos; martes,
9-3, n. 1.141, pp. 1-2: Un viaje a Oriente y en n. ${ }^{\circ} 1.142$; sábado, $12-$ 6, n. ${ }^{1.235}$, pp. 1-3: Un viaje a la sierra de Almagrera; miércoles, 25-8, n. 1.308 , pp. 1-2: Costumbres turcas. El interior de un serrallo; jueves, 18-11, n. 1.391 , pp. 1-3: Recuerdos de la campaña de Egipto.

1842: sábado, 19-3, n. 1.511, pp. 1-2: Viaje a Toledo, N. Magan.

15 1839: domingo, 18-8, n. ${ }^{\circ}$ 548, pp. 1-2: Biografía. Andrés Anderson; viernes, 18-10, n. 609 , p. 1: Mihemet-Ali y también en $n .{ }^{\circ} 892$, p. 1; 1840: miércoles, 8-4, n. 812 , p. 1: Ibrahim-baja; domingo, 12-7, n. ${ }^{\circ}$ 907, pp. 1-3: Vida y trabajos de M. Huskisson y en n. ${ }^{\circ} 909$, pp. 1-2. 1841: lunes, 3-5, n. 1.195 , pp. 1-2: Manolito Gázquez, por El Sevillano; martes, 18-5, n. ${ }^{\circ} 1.210$, p. 1: Bautismo del Conde de Paris. París 11 mayo. Corresponsal.

16 1840: viernes, 26-6, n. 890, pp. 1-3: La muerte del conde de España. Interesantes pormenores sobre el desastroso fin de este hombre sanguinario;

1841: jueves, 7-1, n. 1.080, p. 1: Necrología. Exequias del Sr. D. José Ramón Mackenna y O'Heir (Remiti-

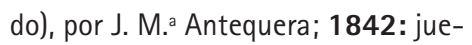
ves, 9-6, n. ${ }^{1.591, ~ p . ~ 1: ~ N e c r o l o g i ́ a . ~}$ El marqués de las Marismas; miércoles, 15-6, n. ${ }^{\circ} 1.597$, pp. 1-2: Folletín (sobre la muerte del general Rafael Ceballos de la Escalera), por Federico de Salazar y Masarrado.

17 1840: martes, 18-8, n. 942, pp. 1-3: Causa criminal contra Madame Lafarge;

1841: martes, 30-11, n. ${ }^{\circ}$.403, pp. 1-3: Causa del regicida Quenisset. El escrito continúa en los siguientes números y aparece siempre en las páginas 1-3: n. ${ }^{0} 1.404$, n. ${ }^{\circ} 1.405$, n. ${ }^{\circ} 1.406$, n. ${ }^{\circ} 1.407$, n. ${ }^{\circ} 1.408$; vier- 
nes, 24-12, n. 1.428 , pp. 1-3: Vista de la causa formada por el Tribunal, n. $1.429, n .^{\circ} 1.430, n .^{\circ} 1.432$, pp. 1-2, n. 1.433, n. 1.434 . Continúa en el año 1842: n. ${ }^{\circ} 1.435$, pp. 1-3: Causa formada al regicida Quenisset y demás cómplices en el atentado cometido al 13 de septiembre contra las vidas de los señores duques de Aumale, de Orleans y de Nemours. Tribunal de los Pares. Audiencia del 9 de diciembre y en el n. ${ }^{\circ} 1.436$, pp. 1-3.

18 Todos los artículos incluidos a continuación en que no se indica el autor están firmados por Abenámar. 1838: lunes, 26-11, n. 284, p. 1: Cuádruple alianza; lunes, 3-12, n. ${ }^{\circ}$ 291, pp. 1-2: Un pronunciamiento, sin firma; miércoles, $12-12$, n. 300 , p. 1 : No lo entiendo.

1839: jueves, 28-2, n. 378, p. 1 : Los pudorosos; martes, 5-3, n. 383 , pp. 1-2: El puente de Bellavista; miércoles, 6-3, n. 384 , pp. 1-2: Cosas de estos días, sin firma; sábado, 16-3, n. ${ }^{\circ} 394$, p. 1 : Un jovellanista; martes, 19-3, n. ${ }^{\circ} 397$, p. 1: El mes de mayo; domingo, 24-3, n. ${ }^{4} 402$, pp. 1-2: Un pedacito de infierno, El Estudiante; miércoles, 27-3, n. ${ }^{\circ} 405$, p. 1: Abenámar a L. Felipe; martes, 2-4, n. ${ }^{\circ} 410$, p. 1 : Sancho y Olozaga; jueves, 4-4, n. ${ }^{0} 412$, p. 1: Los protocolos, El Estudiante; viernes, 5-5, n. ${ }^{413,}$ p. 1: Chúpate esa; viernes, 19-4, n. 427 , p. 1: Madrid en cueros; domingo, 21-4, n. 429 , p. 1: Coalición; sábado, 27-4, n. ${ }^{\circ} 435$, p. 1: La empezaron ellos; sábado, 4-5, n. ${ }^{\circ} 442$, p. 1: No hay que hacer caso; martes, 7-5, n. 445 , p. 1: Abenámar, a los cristianos peticionarios; domingo, 12-5, n. 450 , p. 1: Folletín; jueves, 16-5, n. ${ }^{\circ} 454$, pp. 1-2: Ultramar y en n. ${ }^{\circ} 455$, pp. $1-3$, sin firma; domingo, 2-6, n. 471 , p. 1 : Me estoy durmien- do; martes, 4-6, n. 473 , p. 1: Que pase la nube; martes, 11-6, n. ${ }^{\circ} 480$, pp. 1-2: De la disolución de las Cortes, por G.T.; martes, 2-7, n. ${ }^{\circ}$ 501, p. 1: Abenámar por esos trigos; martes, $16-7$, n. ${ }^{\circ} 515$, p. 1 : Ya estoy yo aquí; sábado, 20-7, n. ${ }^{\circ} 519$, p. 1: La muerte del Sultán y en n. ${ }^{\circ} 530$, p. 1 : Más Sultán; viernes, 2-8, n. ${ }^{\circ} 532$, pp. 1-2: Algo de elecciones; miércoles, 7-8, n. ${ }^{\circ} 537$, p. 1: Así me gusta; miércoles, $14-8$, n. ${ }^{\circ} 544$, p. 1 : Viva el progreso; viernes, $23-8$, n. ${ }^{\circ} 553$, p. 1 : Figuraciones; martes, 27-8, n. 557 , p. 1: A mis lectores; sábado, 31-8, n. 561 , p. 1: Transacción; miércoles, 4-9, n. ${ }^{\circ} 565$, p. 1: Una ilusión; martes, 17-9, n. ${ }^{\circ}$ 578, p. 1: Una paja; jueves, 26-9, n. ${ }^{\circ}$ 587, p. 1: Abenámar a sus hermanos los electores de Pontevedra; sábado, 28-9, n. ${ }^{\circ}$ 589, p. 1: Paz, ferias y facciosos; martes, 1-10, n. 592 , p. 1: No más farándula; viernes, 4-10, n. ${ }^{\circ} 595$, p. 1: Una proclama; jueves, $10-10$, n. ${ }^{\circ} 601$, p. 1 : El algo y su hijo; martes, 15-10, n. ${ }^{\circ} 606$, p. 1: La paz y la prensa; martes, 2210, n. 613, p. 1 : Un abrazo y un abismo; sábado, 2-11, n. ${ }^{\circ} 624$, p. 1: Musas patrióticas; martes, 5-11, n. ${ }^{\circ} 627$, pp. 1-2: La juventud y el pueblo, G. y T; martes, 12-11, n. ${ }^{\circ} 664$ (634), p. 1: Las tres felicitaciones; jueves, 14-11, n. ${ }^{\circ} 666$, p. 1: Disparates; martes, 1911, n. ${ }^{\circ} 671$, p. 1: Soy ministro; sábado, 23-11, n. ${ }^{\circ} 675$, p. 1: La guerra; jueves, 5-12, n. ${ }^{\circ} 687$, pp. 1-2: No más contribuciones. Diálogo entre un paleto patriota y un usía jovellanista, por uno de los mostenses; viernes, 6-12, n. 688 , p. 1: Hidrofobia progresista; miércoles, 18-12, n. 700, p. 1 : Al folletista labriego; sábado, 21-12, n. ${ }^{\circ} 703$, pp. 1-2: Dos palabras dirigidas al clero español sobre la cuestión electoral; miércoles, 25-12, n. ${ }^{\circ} 707$, p. 1: No hay tu tía; viernes, 27-12, n. ${ }^{709,}$ p. 1: Omnia vincit tempos; domingo, 29-12, n. 711 , p. 1: Avisos importantes; sábado, 4-1, n. 717 , p. 1: De Fr. Gerundio, y de lo que salga; martes, $14-1$, n. ${ }^{\circ} 727$, p. 1 : 1840, por T.

1840: sábado, 30-5, n. ${ }^{\circ} 863$, pp. 1-3: De las tradiciones políticas del pueblo español en este siglo, por José Morales Santisteban; viernes, 17-7, n. ${ }^{\circ}$ 10, p. 1: Fuerzas militares del Egipto moderno, acaba en n. 911. 1841: domingo, 21-3, n. ${ }^{\circ} 1.153$, pp. 1-2: El hombre y sus pasiones; domingo, 11-4, n. ${ }^{\circ} 1.173$, pp. 1-2: Un calavera de la clase media; jueves, 29-4, n. 1.191, pp. 1-3: Las cámaras francesas. París, 20 abril. (De nuestro corresponsal); viernes, 4-6, n. ${ }^{\circ} 1.227$, pp. 1-2: Juntas de Guernica. Continúa en: n. ${ }^{\circ} 1.228$, pp. $1-3$ y n. ${ }^{\circ} 1.230$, pp. 1-2, sin firma; jueves, 9-12, n. 1.412 , pp. 1-3: Discurso, sin firma; lunes, 13-12, n. ${ }^{\circ} 1.416$, pp. 1-3: La trata y la abolición, sin firma.

19 1838: jueves, 6-12, n. 294 , p. 1: Correspondencia popular.

1839: martes, 15-1, n. 334 , pp. 1-3: Correspondencia literaria y artística; martes, 14-5, n. ${ }^{\circ} 452$, p. 1: Abenámar a sus hermanos los pobrecitos del Eco del Comercio y los bienaventurados del Guirigay; miércoles, 22-5, n. ${ }^{4} 460$, p. 1: Folletín, por Abenámar (dirigido a El Mensajero del Pueblo); sábado, 25-5, n. ${ }^{\circ} 463$, pp. 1-3: A un amigo, García y Tassara; martes, 28-5, n. ${ }^{4}$ 466, p. 1: Algo de tienda, por Abenámar; domingo, 9-6, n. ${ }^{\circ} 478$, p. 1: Abenámar a su hermanito el ciudadano estrella; n. 631 , pp. 1-3: Revista gaditana, García y Tassara; domingo, $10-11$, n. ${ }^{\circ} 632$, p. 1 : Carta a mi amigo Juanito en París. El novicio; miércoles, 27-11 n. ${ }^{\circ} 679$, p. 1: Al bienaventurado Eco del co- 
mercio de su hermanito Abenámar y en n. ${ }^{\circ} 685$, p. 1: Abenámar a sus afligidos hermanos los pobrecitos del Eco del comercio; jueves, 26-12, n. ${ }^{\circ} 708$, p. 1: A los redactores de $E I$ Conservador, periódico de Sevilla.

1841: jueves, 11-3, n. ${ }^{\circ} 1.143$, p. 1: Carta a mi amigo Juanito en París. También en: n. ${ }^{0} 1.172$ y n. 1.183 (A mi amigo Juanito en París).

20 1838: sábado, 29-12, n. ${ }^{\circ} 317$, pp. 1-2: Señor editor de El Correo Nacional.

1839: martes, 26-2, n. 376, pp. 1-2: Agárrate que vuelven (Del n. ${ }^{\circ}$ de ayer del capricho periodístico Abenámar y El Estudiante); jueves, 7-3, n. ${ }^{\circ} 385$, pp. 1-3: Biografía española. El príncipe Ali Bey El Abbassi (Don Domingo Badia Leblich). (Del "Semanario Pintoresco" del domingo último); sábado, 10-8-, n. ${ }^{\circ} 540$, p. 1: Réplica, por Manuel González; domingo, 3-11, n. ${ }^{\circ} 625$, pp. 1-3: Carta relativa al estado de la música en Madrid (De Revista y Gaceta musical de Paris).

1840: viernes, 10-1, n. 0 723, pp. 1-3: Comunicado (de Fray Gerundio). Moros en campaña; martes, 23-6, n. ${ }^{\circ} 886$, p. 1: Demolición de los monumentos de Arte, por V.C. (Remitido); viernes, 10-7, n. ${ }^{905}$, p. 1: (Remitido) Sepulcro de un personaje, por L.M.; jueves, 12-8, n. ${ }^{1.295}$, p. 1: El público a Fray Gerundio. (Remitido).

1842: lunes, 10-1, n. 1.444, pp. 1-3: Industria española. Exposición pública de 1841 (Del "Semanario Pintoresco") y en el n. 1.445 también.

21 1838: Suele aparecer en las pp. 1-2: lunes, 19-2, n. 4 , p.1: Boletín de teatros; n. ${ }^{\circ}$ 143: Crítica teatral; n. ${ }^{\circ}$ 179, pp. 1-3: Teatros. La mujer de un artista, de J. de R; n. ${ }^{\circ}$ 195: T. Intrigar para morir (De Fr. Gerundio); n. ${ }^{\circ} 231$, pp. 1-3: T. del Príncipe, por E.G.; n. ${ }^{\circ}$ 257: T. del Príncipe; $.^{\circ} 272:$ T. del
Príncipe; $n .^{\circ} 274$, pp. 1-3: T. del Príncipe; $n .{ }^{\circ} 281:$ T. del Príncipe; $n .{ }^{\circ} 297$ : T. del Príncipe; $n .{ }^{\circ} 307$, pp. 1-3: T. del Príncipe; n. ${ }^{\circ}$ 308: Macbeth; n. ${ }^{\circ} 318$ : T. del Principe.

1839: viernes, 11-1; n. 330: T. del Príncipe; $n .{ }^{\circ}$ 357: T. del Príncipe, por E.G; n. 380 : T., por E.G; n. 390: T. del Príncipe, por E.G; n. ${ }^{\circ}$ 398: T. del Príncipe, por E.G; n. ${ }^{\circ} 461$ : T. del Príncipe, por E.G; n. ${ }^{469}$, pp. 1-3: T. del Príncipe; n. ${ }^{\circ}$ 495: T. del Príncipe; n. ${ }^{\circ}$ 512: T. de la Cruz; n. ${ }^{\circ}$ 538, p. 1: T. del Príncipe, por E.G.

1840: domingo, 19-1, n. ${ }^{\circ} 732$ : De los teatros de Madrid; n. ${ }^{\circ} 757$ : Noticias teatrales. El teatro de Barcelona; n. ${ }^{\circ} 805$, p. 1: La Visionaria, comedia en tres actos en prosa, de D. Juan Eugenio Hartzenbusch; n. ${ }^{\circ} 814$, p. 1: Liceo. Función del miércoles ocho en beneficio del señor Esquivel, por G. Romero y $L ; n .{ }^{8} 856$, pp. 1-3: T., por $S$; n. ${ }^{862}$, pp. 1-3: T., por $S$; n. ${ }^{\circ}$ 864: Función dramática verificada en el Liceo a beneficio de la inclusa; n. 1.005: T., por V. de la Vega; n. ${ }^{\circ} 870$, p. 1: El prestidijitador, por A.; n. ${ }^{\circ} 1.006$, pp. 1-3: T., por V. de la Vega; n. ${ }^{\circ} 1.011:$ T.; n. ${ }^{\circ} 1.028:$ T.; n. ${ }^{\circ}$ 1.035: T.; n. ${ }^{\circ} 1.045: \mathrm{T}$.

1841: martes, 5-1, n. ${ }^{\circ} 1.078$, p. 1: T., por V. de la Vega; n. ${ }^{\circ}$ 1.092: T.: Los polvos de la madre Celestina; n. ${ }^{\circ} 1.106$ : T. de la Cruz; n. ${ }^{\circ}$ 1.133: T.; n. 1.204: T. de la Cruz; n. 1.207 , pp. 1-3: T. del Príncipe; n. ${ }^{\circ} 1.214:$ T.; n. ${ }^{\circ}$ 1.249: T.; n. 1.256, p. 1: T., El contrabandista; n. ${ }^{\circ}$ 1.261: T.; n. ${ }^{\circ} 1.282:$ T.; n. 1.323 :

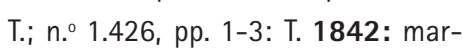
tes, 8-2, n. ${ }^{\circ} 1.473$, pp. 1-3: T. de la Cruz. El zapatero y el rey. 2. ${ }^{\text {a }}$ parte. Drama en cuatro actos por D. José Zorrilla.

22 1839: martes, 16-4, n. ${ }^{\circ}$ 424, pp. 1-3: Cuentos de E.T.A. Hoffman, vertidos al castellano por D. Cayetano Cortés.
Dos tomos en octava prolongado; viernes, 16-8, n. ${ }^{\circ} 546$, y sábado, $17-$ 8, n. ${ }^{\circ} 547$, p. 1: Libro de los niños, por D. Francisco Martínez de la Rosa. 1840: jueves, 7-5, n. 841, p. 1: Critica literaria. El Diablo las carga, cuadro de costumbres, por D. Antonio Ros de Olano, de Z.

1841: domingo, 7-3, n. ${ }^{1.139,}$ pp. 1-3: Crónica literaria; lunes, 153, n. ${ }^{0} 1.147$, pp. 1-2: Cantos del trovador, por D. José Zorrilla. Art. 1. , por G. Garcia y Tassara, y en n. ${ }^{\circ} 1.151$, pp. 1-3; lunes, 12-4, n. 1.174 , pp. 1-3: Ensayos poéticos, de D. Salvador Bermúdez de Castro. Art. 1. ${ }^{\circ}$, por G. García y Tassara y en n. ${ }^{\circ} 1.175$, pp. 1-2; domingo, 18-4, n. 1.180 , pp. 1-2: Tradiciones populares de España, por D. Gregorio Romero Larrañaga, de G. García y Tassara; jueves, 22-4, n. 1.184, pp. 1-3: Crónica literaria. Numismática, Historia, Filosofía moral y Política. París, 10 de abril (De nuestro corresponsal); viernes, 23-4, n. 1.185, pp. 1-2: Crónica literaria. Nuevas producciones de Charles Nodier...; miércoles, 28-4, n. ${ }^{\circ} 1.190$, pp. 1-2: Historia de la Literatura española, por G. García y Tassara; domingo, 13-6, n. 1.236 , pp. 1-3: Crónica literaria.

1842: miércoles, 19-1, n. ${ }^{1.453,}$ pp. 1-3: Crítica literaria. Cuentos por D. Antonio Ros de Olano. Art. 1. ${ }^{\circ}$ Ildefonso Ovejas y en n. ${ }^{\circ} 1.454$.

23 1838: domingo, 18-2, n. ${ }^{\circ}$ : Poesía, de José Zorrilla; n. 6: La isla desierta, de Enrique Gil y Carrasco; n. 27, p. 4: La mariposa, de Enrique Gil; n. ${ }^{\circ}$, p. 1: Un ensueño, de Enrique Gil; n. ${ }^{\circ} 87$, p. 1: El honor, de Francisco González Elipa; n. ${ }^{109}$, p. 3: La eternidad, de Antonio Ferrer; n. ${ }^{\circ}$ 189, pp. 1-3: A Burgos, de J. Guillén Buzarán; n. ${ }^{\circ}$ 201: La nube blanca, E. Gil; n. ${ }^{\circ} 236:$ Meditación, 
de E. Gil; n. ${ }^{\circ} 243$, p. 1: Versos insertos en el album de una señora. La mujer y la niña, de E.Gil.

1839: domingo, $31-3$, n. ${ }^{\circ} 408$, p. 1 : Batalla de los capotes con las capas, por Abenámar y acaba en n. ${ }^{\circ} 436$, p. $1 ;$ n. 417: A la torre de Santa María de Marchena, por A.R.R; n. ${ }^{\circ}$ 459, p. 1: El desierto, por Abenámar; n. ${ }^{\circ}$ 511, p. 1: En el campo, por Gabriel García y Tassara; n. ${ }^{\circ} 525$, p. 1 : Un sauce, por A.R.R.; n. ${ }^{\circ}$ 552: A una fuente, por A.R.R.; n. ${ }^{\circ}$ 564, pp. 1-2: La ilusión, G y T.; n. ${ }^{\circ}$ 575: A la paz, de G. Romero y L.; n. ${ }^{\circ} 704$, pp. 1-3: A los poetas, por G. García y Tassara.

1840: miércoles, 1-1, n. ${ }^{\circ} 714$, p. 1 : El desvelo, por Garcia y Tassara; n. ${ }^{\circ} 716$, p. 1: El amor, de Salvador Bermúdez de Castro; n. 744: Poesías, entresacadas de las obras de Alfonso de La Martine, por G. y T. continuado en el n. ${ }^{\circ} 745 ;$ n. ${ }^{\circ} 850$, p. 1: Poesía, por E.0.; n. ${ }^{\circ} 895$, p. 1: Octavas de un poema, cuyo argumento pertenecía a las Cruzadas, por G. y Tassara.

1841: martes, 24-11, n. 1.036, pp. 1-2: A S.M. la Reina Doña María Cristina, por J.M. Díaz; jueves, 20-5, n. ${ }^{1}$ 1.212, pp. 1-3: Esvero y Almedora. Poema de doce cantos por D. Juan

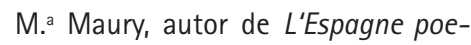
tique, continuado en n. 1.233 y n. ${ }^{\circ}$ 1.234, pp. 1-2. 1842: jueves, 243, n. ${ }^{\circ} 1.516$, pp. 1-2: Canto bíblico, por Gabriel García y Tassara.

24 1838: viernes, 14-9, n. ${ }^{\circ}$ 211, p. 1: El ruiseñor preso, de José Grijalva; viernes, 9-11, n. 267 , pp. 1-3: El Conde Rodulfo, de J.M. de Mas y Casas; sábado, 10-11, n. ${ }^{\circ} 268$, p. 1: La voz del ángel, de Gil Carrasco; miércoles, 12-12, n. ${ }^{\circ} 300$, en Variedades: Un episodio de la guerra civil del s. XVII, cap.I y II, p. 4. y en n. ${ }^{\circ} 304$, pp. 1-2, cap. III; miércoles, 26-12, n. 314 , pp. 1-3: Una aventura sucedida al
Infante Don Juan Manuel, por J.M. de Mas y Casas. Continúa en n. ${ }^{\circ} 315$, pp. 1-2.

1839: lunes, 21-1, n. 340, pp. 1-3: El capitán Makater. Anales marítimos; sábado, 16-2, n. 366 , pp. 1-3: Madama Laura; domingo, 17-2, n. ${ }^{\circ} 367$, pp. 1-3: En la sección folletín aparece Variedades. La molinerilla, por J. M. de Mas y Casas; viernes, 21-6, domingo, 24-2, n. ${ }^{\circ} 374$, pp. 1-3: Escenas de la revolución francesa, que continúa en: n. 377, n. ${ }^{\circ} 381$, n. ${ }^{\circ} 386$, n. ${ }^{\circ}$ 502, n..$^{\circ}$ 504, n. 505 y n. ${ }^{\circ} 509$; sábado, 9-3, n. ${ }^{0} 387$, pp. 1-3: Justicia rusa en Polonia; n. ${ }^{\circ}$ 490, pp. 1-3: Prueba de afecto dada por una mujer a su marido; martes, 9-7, n. ${ }^{\circ}$ 508, pp. 1-2: El cura Bonaparte. Anécdota histórica; martes, 23-7, n. ${ }^{\circ} 522$, pp. 1-3: La lámpara de Lalia; jueves, 1-8, n. 531, pp. 1-3: Una muger de moda, por Mad. Ancelot; miércoles, 21-8, n. ${ }^{\circ 51,}$ pp. 1-2: Sofía CrebiIlon; domingo, 1-9, n. ${ }^{\circ}$ 562, pp. 1-3: El Psilo; viernes, 11-10, n. ${ }^{\circ}$ 602, pp. 1-3: Impresiones de un día de otoño, por G. y T.; domingo, 13-10, n. ${ }^{\circ} 64$, pp. 1-2: Inteligencia de los animales. Dos perros sabios (1) (Del suplemento de la Gaceta de Francia, obra de Eugenio Briffaut); viernes, 15-11, n. ${ }^{\circ} 667$, p. 1: Fantasía, por J.M.D; jueves, 12-12, n. ${ }^{\circ} 694$, pp. 1-3: Los thugs de la India; martes, 24-12, n. ${ }^{\circ}$ 706, pp. 1-3: La cruz, de Salvador Bermúdez de Castro.

1840: sábado, 7-3, n. 780 , pp. 1-3: La reina de los bonis, por J.B.; domingo, 8-3, n. 781, pp. 1-2: El último asilo del infortunio, por J.B.; viernes, 203, n. ${ }^{\circ}$ 793, pp. 1-2: La luna de enero. Cuento romántico, por J.N.V.; martes, 24-3, n. ${ }^{\circ}$ 797, pp. 1-2: La noche, por G. García y Tassara; domingo, 24-5, n. ${ }^{\circ}$ 857, pp. 1-2: Carlitos. Problema social, por A.; viernes, 21-8, n. ${ }^{\circ}$ 945, pp. 1-2: Un matrimonio morganático; lunes, 31-8, n. ${ }^{\circ} 955$, pp. 1-3: El arriero de Bargota. martes, 20-10, n. 1.001, pp. 1-2: El Glaudier;

1841: viernes, 29-1, n. 1.102 , pp. 1-2: Una imprudencia; sábado, 20-3, n. ${ }^{\circ} 1.152$, pp. 1-3: Lisboa y la Corte de Portugal; domingo, 25-4, n. 1.187, pp. 1-2: La marquesa de Guadaira; viernes, 28-5, n. ${ }^{\circ} 1.220$, pp. 1-2: Dios los cría y ellos se juntan, por Félix y Feliciano; martes, 24-8, n. ${ }^{0} 1.307$, pp. 1-2: Napoleón dilettante; jueves, 9-9, n. ${ }^{\circ} 1.322$, pp. 1-2: Una aventura de lord Byron y en 10-12; viernes, 1-10, n. ${ }^{\circ} 1.344$, pp. 1-2: Reflexiones y un cuento, por Pedro Pérez Juana; miércoles, 20-10, n. 1.362, pp. 1-2: La fuente del Gard; martes, 7-12, n. 1.410 , pp. 1-2: Una aventura. Recuerdos de los Estados Unidos. Episodio histórico y n. ${ }^{\circ} 1.411$, pp. 1-3; n. ${ }^{\circ} 1.413$, pp. 1-2: Una noche de Lord Byron, continuada en n. ${ }^{\circ} 1.414$; domingo, 26-9, n. ${ }^{\circ} 1.339$, pp. 1-2: Madame Necker.

25 Sobre la naturaleza de los géneros narrativos aparecidos en esta sección establece Rubio Cremades: "Durante el romanticismo se produce en España una revitalización de los géneros narrativos gracias a la utilización del periódico como medio de difusión. La prensa romántica suele introducir en sus respectivos números una sección o apartado en el que tienen lugar los más diversos géneros, desde novelas o cuentos hasta leyendas y artículos de costumbres. No faltan biografías noveladas ni relaciones históricas descritas como si de un relato novelesco se tratara, relegándose la precisión cronológica o el dato histórico a un segundo lugar para ofrecer así una mayor amenidad en la propia redacción del texto". "El Semanario Pintoresco Español: el artículo 
de costumbres y géneros afines", AlH. Actas XII (1995), p. 248. cvc. cervantes.es/literatura/aih/pdf/12/ aih_12_4_033.pdf.

26 1838: miércoles, 14-3, n. ${ }^{\circ} 27$, pp. 3-4: Literatura egipcia. Los cuatro talismanes. Sigue en: $n .{ }^{\circ} 73$, pp. 1-2 -se hace referencia al n. ${ }^{\circ} 27$ en cuyo suplemento aparece la primera parte de este relato-; n. ${ }^{0}$ 74, pp. 1-2, n.o 51, pp. 3-4, en Variedades. Jornada $3 .^{\text {a }}$ y última; viernes, 2-11, n.o 260, pp. 1-3: Una flor. Novela original de costumbres. Esta obra presenta entregas anteriores publicadas en la sección Variedades del periódico (p. 4) este mismo año 1838: n. ${ }^{\circ} 226$, n. ${ }^{\circ} 228$, n. ${ }^{\circ} 229$, n. ${ }^{\circ} 231, n .^{\circ} 233, n .{ }^{\circ} 234, n .{ }^{\circ} 238$. En el espacio folletín aparecen: $n .{ }^{\circ} 261$, pp. $1-2 ;$ n. 263 , pp. $1-3 ;$ n. 279 , pp. 1-2; n. ${ }^{\circ} 280$, pp. 1-2. J.M. Díaz; lunes, 12-11, n. ${ }^{\circ} 270$, pp. 1-3: Fantasía. El anochecer en San Antonio de la Florida y n. ${ }^{\circ} 271$, pp. 1-2.

1839: sábado, 2-2, n. 352 , pp. 1-2: Los amores de un ruiseñor y una rosa. I Parte. En el n. ${ }^{\circ} 354$, esta novela se traslada a la sección de Variedades, pp. 3-4; martes, 12-2, n. 362 , pp. 1-2: Margarita. Es iniciada su publicación en Variedades, n. ${ }^{\circ} 361$, p. 4, y continuada en esta misma sección de la última página en el n. ${ }^{\circ} 363$, para en el n. 365 volver al folletín; sábado, 15-6, n. ${ }^{\circ} 484$, pp. 1-3: El amor misterioso. Sigue en: n. ${ }^{\circ} 485, n .^{\circ} 487, n .^{\circ} 489$; domingo, 11-8, n. 541, pp. 1-3: Recuerdos de un ciego (1) y el segundo texto en n. ${ }^{\circ} 543$; domingo, 25-8, n. 555, pp. 1-2: Un enemigo oculto y en n. ${ }^{\circ}$ 560, pp. 1-2; domingo, 24-11, n. ${ }^{\circ}$ 676, pp. 1-3: El contrabandista, y en $n .{ }^{\circ} 678$ y n. ${ }^{\circ} 682$; domingo, 1-12, n. ${ }^{\circ} 683$, pp. 1-2: Florita. Sigue en: n. ${ }^{\circ} 690$, n. 693 y n. 695.
1840: domingo, 2-2, n. 746 , pp. 1-3: El corsario noble. Termina en $n .{ }^{\circ} 748$; sábado, 15-2, n. 759, pp. 1-2: Un sueño de amores (1). Continuación: n. ${ }^{\circ} 760$, n. ${ }^{\circ} 762$, n. ${ }^{0} 763$, n. ${ }^{0} 764$, n. ${ }^{\circ} 765$, n. 0767, n. 771 y n. ${ }^{\circ} 772$; lunes, 2-3, n. ${ }^{\circ} 775$, pp. 1-3: Cristela y n. ${ }^{\circ} 777$; lunes, $13-4$, n. ${ }^{\circ} 817$, pp. 1-2: La cruz del acecho (I). Continúa en: n. ${ }^{\circ} 818$, n. ${ }^{\circ} 827$, n. ${ }^{0} 828$, n. 829 , n. 844, n. 845 y n. ${ }^{\circ} 849$; miércoles, 15-4, n. 819 , pp. 1-2: Libro de memorias de Elisa. Libro de sus lágrimas, por A.L. Prosigue en: n. ${ }^{\circ} 821$, n. ${ }^{\circ} 822$, n. 825 y n. ${ }^{\circ} 834$; miércoles, 17-6, n. ${ }^{880}$, pp. 1-2: La noche de máscaras. Cuento fantástico, por A. Con dos entregas más: n. 889 y n. ${ }^{\circ} 891$; domingo, 19-7, n. ${ }^{9}$ 912, pp. 1-2: Edith de Falsen (I). Continuación en: n. ${ }^{\circ}$ 914, n. ${ }^{\circ}$ 916, n. ${ }^{\circ}$ 918, n. ${ }^{\circ}$ 919, n. 921, n. 922, n. 923, n. 924 , n. ${ }^{\circ} 925$, n. 926 у n. ${ }^{\circ} 929$; domingo, 9-8, n. 933, pp. 1-2: Dos meses de matrimonio, por lady Blessington. Sigue en: n. 935 y n. ${ }^{\circ} 936$; jueves, 13-8, n. ${ }^{\circ}$ 937, pp. 1-2: Un matrimonio a estocadas y en $n .{ }^{\circ} 938$; sábado, 15-8, n. ${ }^{\circ} 939$, pp. 1-2: El velo de la viuda (I) y en n. 940 (II y III) (Conclusión); sábado, 22-8, n. 946, pp. 1-3: La posada de la baronesa (I). Con entregas en: n. ${ }^{\circ} 947$, n. ${ }^{\circ} 948$, n. ${ }^{\circ} 949$, n. 950 y n. ${ }^{\circ} 951$; viernes, 28-8, n. ${ }^{\circ}$ 952, pp. 1-2: Las dos cartas. Continúa en: n. ${ }^{\circ} 953$, n. ${ }^{\circ} 954$, n. ${ }^{\circ} 956$, n. ${ }^{\circ} 957$, n. ${ }^{\circ} 958$ y n. ${ }^{\circ} 960$; domingo, 13-9, n. 963, pp. 1-2: Los acreedores. Sigue en: n. ${ }^{\circ}$ 964, n. ${ }^{\circ}$ 966, n. ${ }^{\circ}$ 967, n. ${ }^{\circ}$ 968, n. ${ }^{\circ} 969$, n. ${ }^{\circ} 970$, n. 971, n. $972, \quad$ n. $973, \quad$ n. 976 y n. 978; martes, 29-9, n. 979, pp. 1-3: Madame Laffarge, continuada en: n. ${ }^{\circ}$ 980, n. ${ }^{\circ}$ 981, n. ${ }^{\circ}$ 982, n. 983, n. 984, n. 985, n. 986 , n. 987, n. 988 y n. ${ }^{\circ} 989$; martes, 13-10, n. 993 , pp. 1-2: El príncipe
Mazar, seguido en: n. 997; miércoles, 28-10, n. ${ }^{\circ} 1.009$, pp. 1-2: La caza de brujas, n. 1.010 y n. 1.012 ; jueves, 5-11, n. ${ }^{\circ} 1.017$, pp. 1-2: El incendiario de Aveiron. Con entregas en: n. 1.019, n. ${ }^{\circ} 1.020, n .{ }^{\circ} 1.021$, n. ${ }^{\circ} 1.023, \quad$ n. ${ }^{\circ} 1.025, \quad$ n. ${ }^{\circ} 1.027$, n. ${ }^{\circ} 1.029, \quad$ n. ${ }^{0} 1.031, \quad$ n. ${ }^{\circ} 1.032$, n. ${ }^{0} 1.033$ y n. ${ }^{\circ} 1.034$.

1841 : martes, $16-2$, n. ${ }^{\circ} 1.120$, pp. 1-2: Mateo Petit o El beso de despedida. Sus entregas están en: n. ${ }^{0} 1.121$, n. ${ }^{\circ} 1.122$, n. ${ }^{\circ} 1.124$ y n. ${ }^{\circ} 1.126$; viernes, 12-3, n. 1.144, pp. 1-2: La piel de foca y en n. 1.145 ; lunes, 22-3, n. 1.154, pp. 1-3: El secreto de la confesión. Con entregas en: $n .{ }^{\circ} 1.155$, n. $1.160, \quad$ n. $1.161, \quad$ n. ${ }^{\circ} 1.162$, n. $1.163, \quad$ n. $1.164, \quad$ n. ${ }^{\circ} 1.166$, n. 1.167, n. ${ }^{\circ} 1.168$ у п. ${ }^{\circ} 1.169$; domingo, 9-5, n. ${ }^{\circ} 1.201$, pp. 1-2: El secreto de una madre. Continúa en: n. ${ }^{0} 1.202$, n. ${ }^{\circ} 1.203$, n. ${ }^{\circ} 1.205$, n. ${ }^{\circ} 1.208$ y n. ${ }^{\circ} 1.209$; viernes, 21-5, n. 1-213, pp. 1-2: Balcones viejos y nuevos de la Plaza Mayor y n. 223; lunes, 24-5, n. ${ }^{0} 1.216$, pp. 1-2: Los tres salones. Continúa en: $n .{ }^{\circ} 1.218$ y n. 1.221; jueves, 17-6, n. 1.240 , pp. 1-3: El orgullo de un nombre. Sigue en: $n .^{\circ} 1.241, n .^{\circ} 1.242, n .{ }^{\circ} 1.243$, n..$^{1.245,}$ n. ${ }^{0} 1.246, \quad$ n. ${ }^{\circ} 1.248$, n. $1.262, \quad$ n. ${ }^{0} 1.263, \quad$ n. ${ }^{\circ} 1.264$, n. 1.266 y n. 1.267 ; martes, 3-8, n. 1.287, pp. 1-3: Ana de Arcona. Continúa en: n. 1.289, n. ${ }^{\circ} 1.290$, n. ${ }^{1} 1.291, \quad$ n. ${ }^{\circ} 1.294, \quad$ n. ${ }^{0} .296$, n. ${ }^{\circ} 1.298$, n..$^{0} 1.300$ y n. ${ }^{\circ} 1.301$; jueves, $26-8$, n. 1.309, pp. 1-3: La Mulata. Sigue en: n. ${ }^{0} 1.310$, n. ${ }^{\circ} 1.311$ y n. 1.312 ; martes, 31-8, n. ${ }^{\circ} 1.313$, pp. 1-2: Hugo Lawlor o el novio de Varna. Se completa en los números: n. ${ }^{\circ} 1.314$, n. ${ }^{\circ} 1.315$, n. ${ }^{\circ} 1.316$, n. 1.320 y n. ${ }^{\circ} 1.321$; martes, $21-9$, n. 1.334 , pp. 1-2: El Pintor. Las otras entregas en: $n .{ }^{\circ} 1.335$ y $n .{ }^{0} 1.336$; 
sábado, 2-10, n.⒈345, pp. 1-2: Un matrimonio en la alta sociedad. Historia verdadera, y en n. 1.346 ; martes, 5-10, n. 1.348 , pp. 1-3: Las cuatro hermanas. Las entregas de esta obra son: n. ${ }^{\circ} 1.349$, n. ${ }^{\circ} 1.350$, n. ${ }^{0} 1.351$, n. ${ }^{1} 1.352, \quad$ n. $1.354, \quad$ n. 1.355 , n. ${ }^{0} 1.356, \quad$ n. $1.357, \quad$ n. ${ }^{\circ} 1.358$, n. ${ }^{\circ} 1.359, \quad n .0^{\circ} 1.361, \quad n .{ }^{\circ} 1.363$, n. ${ }^{1} 1.364, \quad$ n. $1.365, \quad$ n. 1.366 , n. ${ }^{0} 1.367$, n. ${ }^{0} 1.369, \quad$ n. ${ }^{0} 1.374$, n. ${ }^{0} 1.376, \quad$ n. ${ }^{0} 1.377, \quad$ n. 1.379, n. ${ }^{\circ} 1.381, \quad$ n. $1.382, \quad$ n. 1.383 , n. ${ }^{\circ} 1.384, \quad$ n. $1.387, \quad$ n. 1.388 , n. ${ }^{\circ} 1.389, \quad$ n. ${ }^{\circ} 1.392, \quad$ n. 1.393 , n. $1.395, \quad$ n. ${ }^{\circ} 1.396, \quad$ n. ${ }^{\circ} 1.398$, n. ${ }^{\circ} 1.401$ y $n .{ }^{0} 1.402$; jueves, 28-

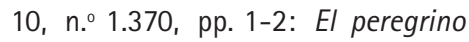
de Suiza, y en n. ${ }^{\circ} 1.371$ y n. ${ }^{\circ} 1.372$; martes, 14-12, n. ${ }^{\circ} 1.417$, pp. 1-3: Un corsario. Bajo el imperio del terror. Se completa con: n. ${ }^{\circ} 1.418$, n. ${ }^{\circ} 1.419$, n. ${ }^{\circ} 1.423$ y n. ${ }^{\circ} 1.424$.

1842: miércoles, 26-1, n. 1.460 , pp. 1-3: El Caballero d'Harmental. Novela en cuatro partes. El resto en: n. ${ }^{\circ} 1.461$, n. ${ }^{\circ} 1.462$, n. 1.463 , n. ${ }^{0} 1.464, \quad$ n. ${ }^{0} 1.465, \quad$ n. ${ }^{\circ} .466$, n. ${ }^{1.467,}$ n. ${ }^{\circ} 1.468$, n. 1.469 , n. 1.470 , n. 1.471 , n. 1.472 ; PARTE 2.: n..$^{\circ} 1.479$, n..$^{\circ} 1.480$, n. ${ }^{\circ} 1.481$, n. ${ }^{\circ} 1.482, \quad$ n. $1.483, \quad$ n. 1.484 , n. ${ }^{1.486,}$ n. ${ }^{\circ} 1.487$, n. 1.489 , n. ${ }^{0} 1.490$, n. ${ }^{\circ} 1.493$, n. 1.494, n. ${ }^{1.495}$, n. ${ }^{\circ} 1.496$, n. 1.497 , n. 1.498; PARTE 3.: n. ${ }^{\circ}$ 1.499, n. ${ }^{\circ} 1.500, \quad n \cdot{ }^{\circ} 1.501, \quad n \cdot{ }^{\circ} 1.503$, n. ${ }^{0} 1.504$, n. ${ }^{\circ} 1.506$, n. 1.507 , n. ${ }^{0} 1.508, \quad$ n. ${ }^{\circ} 1.509, \quad$ n. ${ }^{\circ} 1.512$, n. ${ }^{\circ} 1.513$, n. ${ }^{\circ} 1.513$ (sic), n. ${ }^{\circ} 1.519$, n. ${ }^{1.520 ;}$ 4. ${ }^{\text {a }}$ PARTE: n. ${ }^{\circ} 1.521$, n. $1.523, \quad$ n. ${ }^{\circ} .524, \quad$ n. ${ }^{\circ} 1.525$, n. ${ }^{0} 1.527$, n. ${ }^{\circ} .528$, n. 1.529 , n. ${ }^{0} 1.530, \quad n \cdot{ }^{\circ} 1.531, \quad n \cdot{ }^{\circ} 1.534$, n. 1.535, n. 1.536, n. 1.538 ; lunes, 18-4, n. 1.541 , pp. 1-3: Consuelo. Cuento, por Jorge Sand. Con entre- gas en: $n .^{\circ} 1.542, n .^{\circ} 1.544, n .^{\circ} 1.545$, n. $1.546, n .^{\circ} 1.548$ yn. 1.550 ; miércoles, 4-5, n. 1.557, pp. 1-3: Los novios. Novela de Federico Soulié. Continuación en: n. ${ }^{\circ} 1.558$, n. ${ }^{\circ} 1.559$, n. ${ }^{\circ} 1.560$, n..$^{1.562,}$ n. ${ }^{\circ} 1.563, \quad$ n. $1.564 ; 2{ }^{a}$ PARTE: $n .{ }^{0} 1.565$, n. ${ }^{\circ} 1.566$, n. ${ }^{\circ} 1.568$, n. ${ }^{\circ} 1.570, \quad$ n. ${ }^{0} 1.571, \quad$ n. ${ }^{\circ} 1.573 ; \quad 3{ }^{a}$ PARTE: n. ${ }^{\circ} 1.574, n .^{\circ} 1.575, n .^{\circ} 1.578$, n. ${ }^{\circ} 1.581$, n. ${ }^{\circ} 1.582$, n. ${ }^{0} 1.583$. FIN.; sábado, 4-6, n. ${ }^{\circ} 1.586$, pp. 1-3: Lord Virley. Con entregas en $n .{ }^{0} 1.587$ y n. 1.588 ; viernes, 10-6, n. ${ }^{\circ} 1.592$, pp. 1-2: Paulina de Rubens. La obra continúa en: n. ${ }^{\circ} 1.593$, n. ${ }^{\circ} 1.595$ y n. 1.596 .

27 En muchas ocasiones estos anuncios se realizan en el propio cuerpo de la sección, antes del texto correspondiente a la novela en curso de publicación. Así, por ejemplo, valga el siguiente anuncio del periódico madrileño El Clamor Público que figura a modo de "Advertencia" antes de la entrega de la novela del día: "El miércoles 6 próximo concluiremos de publicar la novela LA CABAÑA DEL TIO TOMAS a la cual seguirá una muy interesante de Mr. Alejandro de Lavergue, titulada TRISTAN D. MORVILLIERS. La falta de las sesiones de Cortes nos permitirá dar más extensión a esta parte de nuestro periódico: al efecto tenemos preparadas novelas de gran celebridad como EL BECERRO DE ORO de Federico Soulié, que publicaremos inmediatamente" (n. ${ }^{\circ}$ 2.678, 10-4-1953, p. 1). 0 bien, en el mismo periódico, con la misma presentación y ubicación que el anterior y como continuación de éste aparece: "Como ofrecimos a nuestros suscritores, empezaremos a dar hoy la interesante novela póstuma de Federico Soulié, titulada El Becerro de Oro, cuya publicación en
Francia ha valido nuevos elogios a su autor. Entretanto traduciremos la segunda parte de Fernando Duplessis o Memorias de un marido, de la que nos disponemos a hacer la apología, habiendo sido acogida la primera con tanta aceptación". (n. ${ }^{\circ}$ 2.728, 9-6-1853, p. 1).

28 www.somosmalasana.com/etiquetas/museo-del--romanticismo/. El folletín del MR (V). 9 junio de 2011 escrito por somosmalasaña. com: "Durante esta semana, entregas diarias de una pequeña historia que narra la llegada al Museo del Romanticismo de una misteriosa pieza de arte, un retrato llamado a ser una de las joyas de la casa. El misterio será desvelado el próximo lunes". PRIMERA ENTREGA: Su Distinguida señoria. El descubrimiento; SEGUNDA ENTREGA: Su Distinguida señoría. La petición; TERCERA ENTREGA: Su Distinguida señoría. La puesta a punto del palacio; CUARTA ENTREGA: Su Distinguida Señoría. El rendez-vous; QUINTA ENTREGA: Su Distinguida Señoría. Los últimos retoques antes del gran día (junio, 2011).

\section{BIBLIOGRAFÍA}

Brunori, Vittorio (1980): Sueños y mitos de la literatura de masas. Análisis crítico de la novela popular, Barcelona, Gustavo Gili.

Lecuyer, Marie Claude y Villapadierna, Maryse (1995): "Génesis y desarrollo del folletín en la prensa española", Magnien, Brigitte: Hacia una literatura del pueblo: del folletín a la novela (EI ejemplo de Timoteo Orbe), Barcelona, Antrhopos, pp. 15-45.

Monguió, Luis (1951): "Crematística de los novelistas españoles del siglo XIX", 
Revista Hispánica Moderna, XVII, Rubio Cremades, Enrique (1995): "El Semapp. 111-127.

Romero Tobar, Leonardo (1973): "Forma y contenido en la novela popular: Ayguals de Izco", Prohemio, 3 (abril), pp. 45-90. nario Pintoresco Español: el artículo de costumbres y géneros afines", AlH. Actas XII, p. 248. cvc.cervantes.es/literatura/aih/pdf/12/aih_12_4_033.pdf
Urzainqui, Inmaculada (1995): "Un nuevo instrumento cultural: la prensa periódica", La república de las letras en la España del s. XVIII, Madrid, Monografías 16, CSIC. 